\title{
ciências humanas e sociais em revista
}


Reitor

Ricardo Motta Miranda

Vice-reitora

Ana Maria Dantas Soares

Pró-Reitora de Pesquisa e Pós-Graduação

Áurea Echevarria

Editor-Chefe

Adriano Lucio Peracchi

Conselho Editorial da EDUR

Adivaldo Henrique da Fonseca

Alexandre L. Guedes

Ariane Luna Peixoto

Ignacio Hernan Salcedo

João Frederico Meyer

Raimundo Braz Filho

Raimundo Nonato Santos

Conselho Editorial da Revista

Antônio Carlos Amorim/UFRRJ

Fernando de Oliveira Vieira/UFF

Mauro Guimarães/UFRRJ

Lana Claudia de Souza Fonseca/UFRRJ

Lucília Augusta Lino de Paulo/UFRRJ

Marco Antônio Leandro Borzano/UEFS

Olívia Maria Gomes da Cunha/UFRJ

Raquel Soihet/UFF

Saturnino de La Torre/Univ. de Barcelona

Sissi Aparecida Martins Pereira/UFRRJ

\section{EDUR}

Editora da Universidade Federal Rural do Rio de Janeiro

Br 465, Km. 7, Campus Universitário - Seropédica - RJ - CEP: 23.890-000 - sala 102/ pavilhão central

Telefone: (021) 2681-4711

Site: www.editora.ufrrj.br

E-mail: edur@ufrri.br
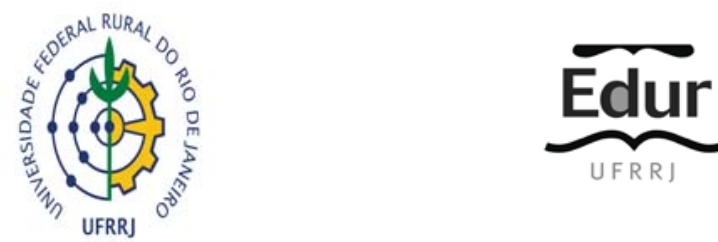
ciências humanas e sociais em revista

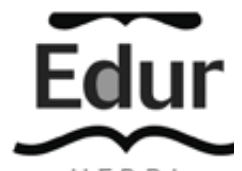


Todos os direitos desta edição reservados à Editora da Universidade Federal Rural do Rio de Janeiro. É proibida a duplicação ou reprodução deste volume, ou de parte do mesmo, sob quaisquer meios, sem autorização expressa da editora.

Os textos expressam a opinião dos autores.

Ciências Humanas e Sociais em Revista

www.ufrri.br/SEER

e-ISSN 2177-756X

Editores Associados

Angela Marina Bravin dos Santos/UFRRJ

Caetana Damasceno/UFRRJ

Cláudio de Sá Capuano/UFRRJ

Clinio de Oliveira Amaral/UFRRJ

Marcelo Almeida Bairral/UFRRJ

Patrícia Reinheimer/UFRRJ

Sabrina Marques Parracho Sant'Anna/UFRRJ

Organizadores do Dossiê

Vânia Maria Losada Moreira, Helen Osório e Adriano Luiz Duarte

Coordenação Editorial:

Sandra Cristina Marchiori Antunes

Projeto Gráfico da Capa: Alexandre Linhares Guedes

Revisão Ortográfica e Gramatical: Alline do Carmo Barbosa Lemos de Assis

Revisão de Inglês: Natália Mano Goulart Saraiva

Diagramação: Jessica Giuliani de Oliveira

Depósito Legal na Biblioteca Nacional

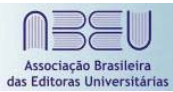

Editora Filiada à ABEU

Associação Brasileira de Editoras Universitárias

Informações gerais: C I Ê N C I A S H U M A N A S E S O C I A I S E M R E V I S T A (e-ISSN 2177-756X) é um órgão oficial da Universidade Federal Rural do Rio de Janeiro, publicada pela EDUR - Editora da Universidade Rural. Sua publicação é semestral com versão apenas on line, contendo trabalhos originais de pesquisa básica e aplicada sobre Ciências Humanas e Sociais. Os artigos devem ser submetidos através do Portal Editorial Costa Lima, no endereço eletrônico www.ufrrj.br/SEER

\section{FICHA CATALOGRÁFICA}

Ciências Humanas e Sociais em Revista - v.34, n. 2, jul./dez., 2012. Seropédica (RJ): Editora Universidade Rural, 2012: il.

Semestral.

Continuação da Revista Arquivos da Universidade Federal Rural do Rio de Janeiro, v. 1-15, 1971-1992. ISSN: 0100-2481. Anual.

ISSN 21751196 